\section{Psychotherapy and Psychosomatics}

Received: November 10, 2011

Accepted after revision: March 2, 2012 Published online: September 9, 2012

Psychother Psychosom 2012;81:394-395

DOI: $10.1159 / 000337747$

\title{
Distinct Functional and Structural Cerebral Abnormalities in Eating Disorders in the Light of Diagnostic Classification Systems
}

\author{
Andreas Joos ${ }^{\mathrm{a}}$, Barbara Saum ${ }^{\mathrm{a}}$, Armin Hartmann ${ }^{\mathrm{a}}$, \\ Oliver Tüschere, ${ }^{\mathrm{d}}$, Ludger Tebartz van Elst ${ }^{\mathrm{b}}$, Almut Zeeck ${ }^{\mathrm{a}}$ \\ a Department of Psychosomatic Medicine and Psychotherapy, \\ ${ }^{b}$ Department of Psychiatry and Psychotherapy, Section for \\ Experimental Neuropsychiatry, and ' Department of Neurology, \\ University of Freiburg, Freiburg, and ${ }^{\mathrm{d}}$ Department of Psychiatry \\ and Psychotherapy, University of Mainz, Mainz, Germany
}

With DSM-5 advancing there is a debate with respect to the classification of eating disorders (EDs). In principle, the categorical approach of DSM-IV will be kept, with anorexia nervosa (AN) and bulimia nervosa $(\mathrm{BN})$ representing the main ED entities. However, there are also rationales to conceptualize ED as a continuum: Most ED patients - independent of diagnostic category - are characterized by an overevaluation of shape and weight, a strong dissatisfaction with their body and an engagement in some form of weight control behavior. They often switch diagnostic categories over time, and there is genetic cross-transmission. Furthermore, about half of ED cases do not fulfill all criteria of $\mathrm{AN}$ or $\mathrm{BN}$. Here we raise the question whether the increasing number of neurobiological studies, in particular imaging data, might contribute to this debate.

One of the first functional magnetic resonance imaging (fMRI) studies was suggestive of functional cerebral substrates common to various EDs, demonstrating increased reactivity of the medial prefrontal cortex [1]. Recent fMRI studies have shown different results. One study that used words concerning body image demonstrated an increased response of the right amygdala in AN, while ventromedial abnormalities characterized BN [2]. Investigations using visual body images yielded amygdalar activation in $\mathrm{AN}$, but not in $\mathrm{BN}[3,4]$. Our group used a food paradigm, which demonstrated an increased response of the right amygdala and decreased signals of the midcingulate cortex in restrictive AN [5], while BN patients had decreased frontocingular and temporal signals [6]. Contrasting these samples directly, BN was characterized by decreased frontocingular activation, as shown in figure 1 . A further recently published fMRI investigation used the active instruction to imagine eating the food shown in the images and compared AN with BN patients [7]. Again, differences in blood oxygen level-dependent signals were demonstrated, which com-

A. Joos and B. Saum contributed equally to this article. L. Tebartz van Elst and A. Zeeck contributed equally as senior authors.

\section{KARGER}

Fax +4161306 1234 E-Mail karger@karger.ch www.karger.com
(C) 2012 S. Karger AG, Basel

$0033-3190 / 12 / 0816-0394 \$ 38.00 / 0$

Accessible online at: www.karger.com/pps

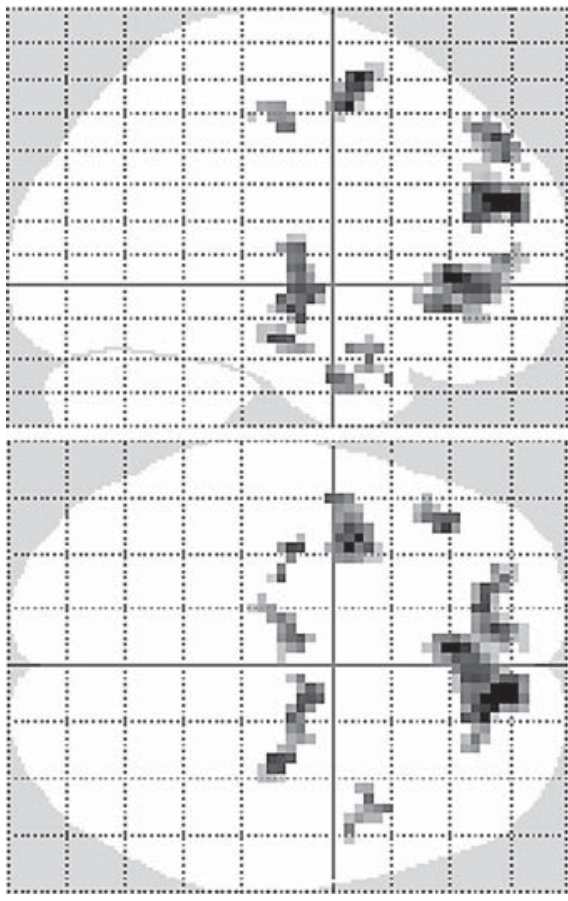

Fig. 1. Group comparisons $A N(n=11)>B N(n=10)$ (food $>$ nonfood). Glas brain (sagittal and horizontal planes, $\mathrm{p}_{\text {uncorr. }}<0.01$ for visualization purposes). A cluster of 110 voxels located at the ventral anterior cingulate cortex reached $\mathrm{p}_{\text {corr. cluster level }}=0.07$, corrected for multiple comparisons across the whole brain [z-value of peak voxel 3.54 at MNI -3 33 0]. For detailed description of imaging acquisition and processing, see Joos et al. [5] and Joos et al. [6]. At a less conservative threshold, i.e. when not correcting for multiple comparisons across the whole brain, two further clusters reached a p value $<0.01$ at the cluster level: the dorsal anterior cingulum [p puncorr. cluster level $=0.003, \mathrm{z}$-value of peak voxel 3.99 at MNI $95121]$ and the left superior frontal lobe [ $p_{\text {uncorr. cluster level }}=0.008$, z-value of peak voxel 3.23 at MNI -9 4822 ].

prised the cingulate cortex as well as the parietal, temporal, insular, supplementary motor and subcortical (caudate nucleus) regions [7]. A photon emission computed tomography study reported almost reverse perfusion patterns of $\mathrm{AN}$ and $\mathrm{BN}$ when subjects were compared in the resting condition and after food intake [8]. Furthermore, using magnetic resonance spectroscopy of the anterior cingulate cortex, $\mathrm{BN}$ patients showed a positive correlation of glutamate with 'drive for thinness', whereas restrictive AN subjects did not [9]. With respect to ventromedial dysfunction (including the anterior cingulate cortex), it should however be kept 
in mind that this occurs in other mental diseases, too [10]. Structural cerebral imaging also demonstrated strong differences between $\mathrm{AN}$ and $\mathrm{BN}$ with reduction of cingular and temporoparietal grey matter in $\mathrm{AN}$ [11], whereas $\mathrm{BN}$ was not affected in whole brain analyses $[11,12]$.

In summary, from a neurobiological imaging point of view, there is evidence of functional and structural cerebral differences between $\mathrm{BN}$ and $\mathrm{AN}$. Considering diagnostic issues, these results seem in favor of keeping a categorical approach. However, a complementary dimensional approach might be reasonable for specific pathopsychological features like drive for thinness, which are shared by most EDs, as shown by a positive correlation of grey matter volume of the right parietal cortex and drive for thinness in both restrictive $\mathrm{AN}$ and $\mathrm{BN}$ [11]. We think that these findings support the notion that biological features should be considered when discussing the classification of psychic syndromes in the future. Furthermore, considering these neurobiological facts might also form a bridge between neurobiological research and clinical thinking.

\section{Disclosure Statement}

The authors declare that no conflict of interest or external financial support exists with regard to this article.

\section{References}

1 Uher R, Murphy T, Brammer MJ, Dalgleish T, Phillips ML, Ng VW, Andrew CM, Williams SC, Campbell IC, Treasure J: Medial prefrontal cortex activity associated with symptom provocation in eating disorders. Am J Psychiatry 2004;161:1238-1246.

2 Miyake Y, Okamoto Y, Onoda K, Shirao N, Okamoto Y, Otagaki Y, Yamawaki S: Neural processing of negative word stimuli concerning body image in patients with eating disorders: an fMRI study. Neuroimage 2010;50:1333-1339.
3 Miyake Y, Okamoto Y, Onoda K, Kurosaki M, Shirao N, Okamoto Y, Yamawaki S: Brain activation during the perception of distorted body images in eating disorders. Psychiatry Res 2010;181:183-192.

4 Vocks S, Busch M, Gronemeyer D, Schulte D, Herpertz S, Suchan B: Neural correlates of viewing photographs of one's own body and another woman's body in anorexia and bulimia nervosa: an fMRI study. J Psychiatry Neurosci 2010;35:163-176.

5 Joos A, Saum B, Tebartz van Elst L, Perlov E, Glauche V, Hartmann A, Freyer T, Tüscher O, Zeeck A: Amygdala hyperreactivity in restrictive anorexia nervosa. Psychiatry Res 2011;191:189-195.

6 Joos A, Saum B, Zeeck A, Perlov E, Glauche V, Hartmann A, Freyer T, Sandholz A, Unterbrink T, Tebartz van Elst L, Tüscher O: Frontocingular dysfunction in bulimia nervosa when confronted with diseasespecific stimuli. Eur Eat Disord Rev 2011, Epub ahead of print.

7 Brooks SJ, O’Daly OG, Uher R, Friederich HC, Giampietro V, Brammer M, Williams SC, Schioth HB, Treasure J, Campbell IC: Differential neural responses to food images in women with bulimia versus anorexia nervosa. PLoS One 2011;6:e22259.

-8 Nozoe S, Naruo T, Yonekura R, Nakabeppu Y, Soejima Y, Nagai N, Nakajo M, Tanaka H: Comparison of regional cerebral blood flow in patients with eating disorders. Brain Res Bull 1995;36:251-255.

-9 Joos A, Perlov E, Büchert M, Hartmann A, Saum B, Glauche V, Freyer T, Weber-Fahr W, Zeeck A, Tebartz van Elst L: Magnetic resonance spectroscopy of the anterior cingulate cortex in eating disorders. Psychiatry Res 2011;191:196-200.

10 Nabeyama M, Nakagawa A, Yoshiura T, Nakao T, Nakatani E, Togao O, Yoshizato C, Yoshioka K, Tomita M, Kanba S: Functional MRI study of brain activation alterations in patients with obsessive-compulsive disorder after symptom improvement. Psychiatry Res 2008;163:236247.

11 Joos A, Klöppel S, Hartmann A, Glauche V, Tüscher O, Perlov E, Saum B, Freyer T, Zeeck A, Tebartz van Elst L: Voxel-based morphometry in eating disorders: correlation of psychopathology with grey matter volume. Psychiatry Res 2010;182:146-151.

-12 Schäfer A, Vaitl D, Schienle A: Regional grey matter volume abnormalities in bulimia nervosa and binge-eating disorder. Neuroimage 2010;50:639-643. 